University of South Carolina

Scholar Commons

Summer 2008

\title{
Graduate Training in Sociological Theory and Theory Construction
}

Barry N. Markovsky

University of South Carolina - Columbia, barry@sc.edu

Follow this and additional works at: https://scholarcommons.sc.edu/socy_facpub

Part of the Sociology Commons

\section{Publication Info}

Sociological Perspectives, Volume 51, Issue 2, Summer 2008, pages 423-445.

This Article is brought to you by the Sociology, Department of at Scholar Commons. It has been accepted for inclusion in Faculty Publications by an authorized administrator of Scholar Commons. For more information, please contact digres@mailbox.sc.edu. 


\title{
GRADUATE TRAINING IN SOCIOLOGICAL THEORY AND THEORY CONSTRUCTION
}

\author{
BARRY MARKOVSKY \\ University of South Carolina
}

\begin{abstract}
Nearly all of sociology's top graduate training programs require their students to complete one or two courses on sociological theory. The instructors for these courses have an extraordinary opportunity to affect the perspectives and practices of future generations of scholars. This study assesses the backgrounds, attitudes, beliefs, and practices of those instructors regarding different approaches to theorizing, with particular attention paid to topics related to science and to theory construction. Sociologists who teach required theory courses in the discipline's top fifty graduate training programs were asked a series of questions pertaining to their own training and to the courses they were teaching: attitudes toward different kinds of theorizing, perceptions of the role that theory plays in sociology and in science, and views on the nature of science. Results indicate a strong consensus on the most important classical theorists (Marx, Weber, and Durkheim). However, attitudes and practices varied widely in regard to other classical theorists, contemporary sociological theory, and the role of scientific standards in the development of sociological knowledge. The author explores some of the implications of these attitudes and practices.

Keywords: theory; theory construction; theory training; science
\end{abstract}

Sociology's published literature reflects a wide range of views on the nature and value of different kinds of theoretical work. By interviewing sociologists who teach required theory courses in the most influential graduate programs, this research addressed conceptions and attitudes about theory and how it is taught. Several questions guided the research: (1) What is being taught as "theory" in our graduate programs? (2) How and where were instructors trained? (3) What do instructors think about current training practices, the role of theory in sociology, classical theory, contemporary theory, formal theory, and science more generally? (4) What do the findings suggest about the prospects for advancement of the field?

Address all correspondence to: Barry Markovsky, Department of Sociology, University of South Carolina, Columbia, SC 29208; phone: (803) 777-0804; e-mail: barry@sc.edu.

Sociological Perspectives, Vol. 51, Issue 2, pp. 423-447, ISSN 0731-1214, electronic ISSN 1533-8673. (C) 2008 by Pacific Sociological Association. All rights reserved. Please direct all requests for permission to photocopy or reproduce article content through the University of California Press's Rights and Permissions website, at http://www.ucpressjournals.com/reprintinfo.asp. DOI: 10.1525/sop.2008.51.2.423. 


\section{Presuppositions}

Sociological knowledge is embodied in theories. The production of theories is a collective endeavor in that they may improve through critical feedback from readers other than their authors. However, critical analyses only improve theories when they serve the following criteria:

Theories should make clear assertions. Collective evaluation is pointless if a theory's terms are not defined in ways that ensure their shared understanding: One can neither validate nor refute a theory unless one's understanding of its statements closely reflects that of its authors.

Theories should be logical. Theories are arguments in that they assert conclusions supported by premises. If a theoretical argument violates standard logical principles, such as by having mutually contradictory premises, then there is no warrant to accept its conclusions.

Theories should be precise, general, and accurate. A theory that makes more specific claims about a wider range of phenomena with greater empirical confirmation is preferable to a theory that does otherwise.

Hereafter, we refer to these as the presuppositions. They are general criteria for a rigorous theory construction methodology, consistent with the requirements of formalization and with science more generally. ${ }^{1}$ It is unfortunate that many sociologists lump them under rubrics of "positivism" and dismiss them with prejudice, for ignoring clarity, logic, precision, generality, and accuracy imperils theories and impedes their progress. ${ }^{2}$ If these qualities are not stressed within the collective evaluation process (most importantly, peer review), then they are unlikely to inhere in our work. Furthermore, absent a concerted interest in these qualities, theories are likely to be selected and maintained on grounds of fashion and politics rather than veracity. Finally, any theory promoted on grounds other than clarity, logic, etcetera deserves to be regarded with skepticism. Even so, the presuppositions should not be applied too rigidly. Although no cogent argument can be made for opacity and illogic in theory building, this does not mean that only perfection is viable. Rather, the presuppositions guide selection among fallible alternative theories and help to identify areas where improvements are needed.

Theories in any field can be weakened through the intrusion of social factors such as politics, economics, incompetence, and fraud. Skeptics of a certain stripe believe that, rather than logic and evidence, social processes determine our theories' content. Undoubtedly, it sometimes does. Still, such a broad conclusion is not warranted. It may be worth keeping in mind that the same impediments can undermine the construction of a house, bridge, skyscraper, or space shuttle, yet these things do get built, they usually function roughly as planned, and upgrades may even improve their operation over time. Why not theories?

\section{ON THEORY}

"Theory" has multiple connotations in our discipline, ranging from summarized observations to chains of mathematical formulae, from broadly received classics to newly minted speculations. To presume that some meanings are more correct 
than others would imply that the word theory has inherent meaning. It does not. Nor must a definition encompass every notion to which the term has ever referred. ${ }^{3}$ Because there are so many referents, however, those who use the term bear a responsibility to communicate what they mean by it. And because some of its current meanings are mutually exclusive, every theorist has to take some stands.

To provide further context for the results presented later, I first discuss some of the services that theories offer to research-oriented disciplines and the conditions for their optimal functioning. The article closes with a discussion of benefits that would be expected to accrue in our graduate training and in our published work from an increased emphasis on the structural and semantic qualities of sociological theories.

\section{Functions and Processes}

Theories are the heart of every discipline. They are lenses through which researchers study their phenomena, sometimes validating what they believed they knew all along and other times revealing the unexpected. Although few sociologists would contest such a broad characterization, what passes for theory in our books and journals indicates a lack of consensus as to their nature and basic functions. To those who agree that disciplines are collective endeavors that advance knowledge in ways isolated individuals cannot, a shared vision of theory, at least among a critical mass of scholars, is essential for advancement. If scholars work at cross-purposes or if the "mass" is subcritical, then the absence of a consensus on theoretical methods hinders progress. ${ }^{4}$

Theory-driven disciplines are collective to the degree that shared conventions and standards guide the development and evaluation of their theories. On the development side, theories are creative accomplishments that benefit from an unrestricted diversity of perspectives. Open mindedness is essential at this stage, with ideas for new theories, or for improving existing theories, coming literally from anywhere and anyone. But at this stage, ideas are only provisional.

Not all provisional theories are equally viable, nor are there ever sufficient resources to pursue them all (Fales and Markovsky 1997). Theories require evaluation before they are accepted, and methods for evaluation necessarily differ from methods for development. The goal is to examine theoretical offerings critically and cull the best from the rest. No theory is acceptable merely because it rings true, and all theories are improvable. It stands to reason that the greater the number of critical eyes focused on even the best theories, the greater the likelihood that weaknesses will be revealed and repairs implemented. This imbues theories with a transcendent quality: a theory can achieve a depth and breadth of understanding that exceeds any individual author's. There is a price, however: evaluating theories entails significant and sustained efforts. Furthermore, the presuppositions are not commonsensical, and their collective adoption does not occur spontaneously.

Evidence presented below indicates that, even among those who teach theory in leading graduate programs, there is little interest in promoting shared standards 
for building and evaluating sociological theories. Some deny outright even the possibility of collective evaluation. To be sure, a theory may be fraught with ambiguities that impede its accurate dissemination, or it may be the case that nobody apart from its author cares about it one whit. Still, these circumstances do not in principle thwart collective evaluation. Furthermore, absent the possibility that theories can be understood uniformly among members of a community of scholars, there literally is nothing-or no one thing-to talk about. Under such conditions, theories are inkblots open to multiple interpretations, and no interpreter has greater claim to truth than any other. The very spirit of theorizing involves intersubjectivity: transferring our insights accurately into the minds of interested others and capitalizing on their insights and abilities to offer corroborations and corrections. The more effectively a discipline elevates, promotes, and applies standards for the objective, collective evaluation of theories, the more efficiently its knowledge improves.

\section{Training in Theory}

Sociology intersects disciplines such as psychology and economics, which routinely benefit from rigorous theories that are formulated and improved in ways consistent with the presuppositions. However, sociology has relatively few such theories (Dilks, Irwin, and Markovsky 2006). Both proponents and detractors of rigorous theorizing may concede that (1) many of sociology's best theories also are its oldest, (2) these theories do not change appreciably over time, and (3) they are not rigorous. This runs counter to the state of affairs in more progressive disciplines where theories are refined incrementally over time in ways that enhance their breadth and precision, and they evolve in ways that demonstrably increase both explanatory power and parsimony (Campbell 1974; Freese 1980). Of the many factors contributing to this situation, a likely cause is located at the nexus of our discipline's newer and older theorists: graduate training programs.

This project interviewed instructors of required theory courses in the top U.S. graduate programs of sociology. Resource limitations prohibited a more extensive sample, although it may not have mattered anyway. Results indicate that the upper echelon programs have an enormous impact on the perpetuation of the discipline's orientations and practices. That is where practically all leading American sociologists received their theory training and where course requirements impart what their programs believe to be crucial information. These courses are where received knowledge is transmitted across intellectual generations.

As noted earlier, disciplines orient themselves around ideas that, implicitly or explicitly, come to be embodied in their theories. Only the most radical of empiricists believe that "data speak for themselves" without the benefit of, at minimum, perspectives, orientations, metatheories, frameworks, or other such quasi-theoretical forms. Most social scientists have come to accept that theoretical ideas provide meaning and purpose for empirical observations. ${ }^{5}$ Therefore, if sociology has an intellectual core embodying our approach to understanding the social world, then it ought to be evident in theory courses required for future scholars in the 
field. We should expect these understandings to be distilled, packaged, and distributed through the compulsory courses of our flagship graduate programs. These are the interface between sociology's body of accumulated knowledge and the forthcoming generation of scholars who will later employ that knowledge and disseminate it to students of their own.

Some of the interview questions addressed respondents' views on approaches consistent with the presuppositions. To the extent that sociology graduate programs offer scientific training, we might suppose that it occurs mainly in courses on research methods and statistics. These teach strategies and techniques for making systematic empirical observations, handling data, building statistical models, and testing hypotheses. They also teach values and practices that are consistent with norms of science-accuracy, precision, and parsimony.

Quantitative and qualitative methods courses provide tools for empirical descriptions and inferences, but the reasons for making particular observations are beyond their scope. These reasons emanate from theories and quasi-theories, the latter including hunches, implicit theories, educated guesses, tacit knowledge, and the like. Without at least that much, we cannot know how to interpret what is observed or even what to observe. The most rigorous of measures has no inherent utility if gathered without purpose. Sound empirical methods are necessary but insufficient for the intellectual growth of disciplines. ${ }^{6}$

When we do encounter work that qualifies as rigorous, nearly always it is rigorous in empirical execution rather than in its theory. Journals commonly publish loosely stated and discursive theoretical ideas spread over multiple pages, then a set of empirical variables interpreted via references to some of the theoretical ideas, leading up to a parsimonious statistical model employing highly refined measures and explicit functional relationships. The variables and relationships are not inconsistent with the theoretical discussion, but neither are they actually entailed by it. The implicit assumptions imposed by statistical methods typically are far more constraining than those imposed by the theoretical ideas they ostensibly test, as when discursive, ordinal-level conjectures are tested with sophisticated multivariate ratio-level measurement models. ${ }^{7}$ The more loosely stated the theory, the easier it is to claim empirical corroboration but the less is actually learned.

This study's design was guided mainly by conjectures, not theory. It exemplifies the kind of pretheoretical research described above, albeit with a special effort to understand attitudes toward the presuppositions. If a case is ever to be made that sociology would benefit from raising its collective interest in theory construction, we need evidence on the state of the art.

\section{METHOD}

To address the central research questions, it was important to probe for the sources of major orientations and practices that diffuse across generations of sociologists. Interviewers targeted instructors of required theory courses in top programs as a means to maximize the value of the data while minimizing costs. Assistants could gather basic information on these courses and on their instructors' 
orientations and also permit interviewees to elaborate on their views in a way not possible with mailed surveys.

\section{Instrument Design and Pretesting}

Subheadings below indicate how the research questions were approached in the interview. Numerical ranges refer to the associated items (see Appendix A). ${ }^{8}$

What is taught? Items on required courses and assignments (1 to 4) gathered information on essential readings, verified that the instructors' course fulfilled a theory requirement, and asked about the adequacy of their own training in theory.

Instructors' training. Instructors were queried about their PhD institutions and the courses they took as graduate students (5 to 6).

Instructors' perceptions and attitudes. Additional blocks of items gathered instructors' views on graduate theory training nationwide (7 to 11), the messages about theory passed along to students (12), the roles that theories play in sociology and in science more generally (13 to 14), the status of sociology as a science (15 to 16), and orientations toward science and theory (17 to 20).

The uncomplicated design of the survey facilitated its pretesting. Project assistants conducted interviews with, and solicited feedback from, several faculty who had taught theory courses. Small adjustments were made to the wording and sequencing of some items, but otherwise, the instrument proved to be clear and straightforward.

\section{Sample}

The project targeted instructors of required theory courses in the top fifty graduate sociology programs in the United States as identified by U.S. News and World Reports. ${ }^{9}$ Most of the instructors also had active publishing careers, writing on theory and various substantive topics.

\section{Data Collection and Transcription}

Project assistants used Web sites, e-mails, and phone calls to build a database of programs and instructors. Initial contacts and interview arrangements with each instructor were made via e-mail whenever possible. Eventually, we reached instructors in forty-eight (96 percent) of the targeted departments. ${ }^{10}$

Interviews were conducted by project assistants and tape recorded with respondents' permission. Most interviews lasted fifteen to thirty minutes, and respondents were encouraged to expand on any of their answers if they wished. After the interview, each had an opportunity to offer comments or to ask questions. An e-mailed version of the interview instrument was sent to theory instructors at twelve additional departments that did not at that point have at least one representative in the sample. Interviews were converted into electronic documents by a professional transcriber, and the e-mailed versions were converted into a comparable format. 


\section{Reliability Check and Data Coding}

Initially, the author and two assistants coded two randomly chosen transcripts independently. Checks were performed on items with Likert and categorical response scales with near-perfect intercoder reliability obtained. ${ }^{11}$ These responses were copied into a master spreadsheet. Items with open-ended responses required a more interpretive approach. The author used a word processor to highlight passages in each response that were most directly relevant to the questions asked. Each of these responses-or else a précis of each response-was copied into a master spreadsheet. This spreadsheet included both numerical and textual data from the interview questions for every respondent.

\section{RESULTS}

This section presents main findings from the interviews, to be followed by a "Discussion" section in which implications are drawn for the questions that motivated the project.

\section{Course Information}

Of the top fifty departments, forty-eight had one or more required graduate theory course, and instructors from forty-six of those forty-eight programs participated. ${ }^{12}$ We interviewed seventy-one instructors, sixty-three by telephone and eight via the e-mailed version of the questionnaire. Twenty-four departments provided one respondent apiece, nineteen departments had two respondents, and three departments had three respondents. Among the seventy-one instructors, forty-two taught a classical theory course, twenty-three taught contemporary theory, four taught theory construction, seven taught a combined contemporary/ classical course, and one taught a combined contemporary/construction course. Six of the instructors taught two different courses: Four taught contemporary and classical courses, one taught contemporary and construction, and one taught classical and construction. Across all courses, the average enrollment was 13.8 students $(S D=4.87)$.

Sixty-four instructors cited a total of 222 theorists or readings, an average of 3.5 per instructor. Forty-five different theorists were named. Of these, twenty-four were cited by only one instructor, and eighteen were cited by from two to nine instructors. Marx, Weber, and Durkheim jointly accounted for 55.9 percent of all citations. Marx was the least cited of the top three (forty times) but still cited far more than the next theorists on the list-Simmel (nine) and Mead (five).

Table 1a shows identical ordinal patterns for the distributions of courses in the sample, essential readings cited, and required courses taken by instructors years earlier. ${ }^{13}$ If graduate students are influenced by the orientations of their instructors and if the discipline is slow to develop theoretically, then these patterns would hold across the decades. Evidence for this appears in Table 1b, comparing the courses and readings taught by the "newest" one-third of the sample $(\mathrm{PhD}<$ thirteen years) to the "oldest" one-third ( $\mathrm{PhD}>$ twenty-four years). Scholars in 
TABLE 1a

Distribution of Emphases in Courses and Readings

\begin{tabular}{lccc}
\hline & Classical & $\begin{array}{c}\text { Modern/ } \\
\text { Contemporary }\end{array}$ & $\begin{array}{c}\text { Theoretical } \\
\text { Methods }\end{array}$ \\
\hline \% of courses in sample & 59.1 & 35.1 & 5.8 \\
\% of cited essential readings & 70.3 & 27.5 & 2.2 \\
\% of courses taken by instructors & 51.4 & 29.7 & 18.9 \\
\hline
\end{tabular}

TABLE $1 b$

Distribution of Course Types and "Essential Readings" by Years since PhD

\begin{tabular}{|c|c|c|}
\hline & Newest PhDs & Oldest PhDs \\
\hline \multicolumn{3}{|l|}{ Courses } \\
\hline$\%$ classical & 52.0 & 55.3 \\
\hline$\%$ modern/contemporary & 44.0 & 42.6 \\
\hline$\%$ theoretical methods & 4.0 & 2.1 \\
\hline \multicolumn{3}{|l|}{ Readings (times cited) ${ }^{\mathrm{a}}$} \\
\hline Durkheim & 12 & 13 \\
\hline Weber & 12 & 13 \\
\hline Marx & 11 & 13 \\
\hline Simmel & 3 & 3 \\
\hline Others cited & 19 & 22 \\
\hline
\end{tabular}

aNo specific "other readings" were cited more than three times within either subsample.

the two groups received their PhDs twenty-five years apart on average but are virtually identical insofar as the distribution of their courses and the frequencies of their cited essential readings. The lack of consensus on the nonclassical readings occurs both within and across generations.

\section{Instructors' Training}

The seventy-one interviewees received degrees from thirty-three departments. Berkeley accounted for eleven instructors (15.5 percent), more than double the number from the next closest departments. A subset of just six departments (Berkeley, Columbia, Chicago, Harvard, Stanford, and Wisconsin) accounted for thirty-five (49 percent) of the instructors, and fifty-one (72 percent) of the instructors received PhDs from just thirteen departments—the above six plus Michigan, UCLA, Cornell, Oxford, Penn, Stony Brook, and University of California, San Diego. ${ }^{14}$ This pattern is very similar for earlier versus later PhDs: Dividing the sample in half according to years since the PhD, 51 percent of the newer instructors and 49 percent of the older instructors came from the same set of six departments; 71 percent of the newer PhDs and 74 percent of the older PhDs came from the same thirteen departments. 
TABLE 2

Was Respondent's Theory Training Adequate?

\begin{tabular}{|c|c|c|}
\hline Response & Frequency & Proportion \\
\hline Yes & 47 & $67.1 \%$ \\
\hline No & 20 & $28.6 \%$ \\
\hline Marginal & 3 & $4.3 \%$ \\
\hline Omitted & 1 & \\
\hline \multicolumn{3}{|c|}{ If "no," then why? ( $n=20 ; 23$ responses) } \\
\hline \\
\hline \multicolumn{3}{|c|}{$21.7 \%$ deficient in cla } \\
\hline \multicolumn{3}{|c|}{$17.4 \% \quad$ (not specified) } \\
\hline \multicolumn{3}{|c|}{$13.0 \%$ self-taught } \\
\hline \multicolumn{3}{|c|}{ leficient in theory con } \\
\hline \multicolumn{3}{|c|}{$4.3 \%$ unbalanced } \\
\hline \multicolumn{3}{|c|}{$4.3 \%$ instructor bias } \\
\hline \multicolumn{3}{|c|}{$4.3 \%$ my own fault } \\
\hline \multicolumn{3}{|c|}{$4.3 \%$ not required } \\
\hline
\end{tabular}

\section{Instructors' Views}

\section{Quality of Training}

Table 2 indicates that two-thirds of respondents were satisfied with their own graduate theory training. ${ }^{15}$ The minority who felt otherwise cited a variety of reasons, as summarized in the lower portion of the table. ${ }^{16}$

Table 3 reports instructors' beliefs about the quality of different forms of theory training in the United States. The question posed to the first ten respondents only inquired about classical theory, theory construction, and formal logic. "Contemporary theory" was then added after a number of those first respondents expressed distinct opinions about it. Overall, respondents indicated that training

TABLE 3

Quality of Graduate Training Nationally

\begin{tabular}{lcccc}
\hline & $\begin{array}{c}\text { Contemporary } \\
\text { Theory }\end{array}$ & $\begin{array}{c}\text { Classical } \\
\text { Theory }\end{array}$ & $\begin{array}{c}\text { Theory } \\
\text { Construction }\end{array}$ & $\begin{array}{c}\text { Formal } \\
\text { Logic }\end{array}$ \\
\hline$M$ & 2.55 & 2.52 & 2.01 & 1.81 \\
$S D$ & .90 & .84 & .83 & .90 \\
$n$ & 44 & 46 & 44 & 42 \\
Don't know & 14 & 22 & 25 & 24 \\
No answer & 2 & 2 & 2 & 2 \\
Omitted & 11 & 1 & 0 & 3 \\
\hline
\end{tabular}

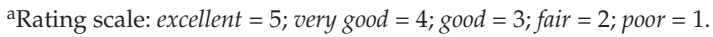

Other responses: "Don't know": respondent stated he or she could not respond because of insufficient information. "Omitted": question was omitted in initial interviews. "No answer": respondent chose not to respond for any other reason. 
TABLE 4

More Theory Training for Grad Students?

\begin{tabular}{|c|c|c|}
\hline Response & Frequency & Proportion \\
\hline Yes & 55 & $87.3 \%$ \\
\hline No & 8 & $12.7 \%$ \\
\hline Don't know; no answer & 8 & \\
\hline \multicolumn{3}{|c|}{ If "yes," then in what areas? ( $n=55 ; 63$ responses) } \\
\hline$\%$ of Respondents & Cited Area & \\
\hline 25.4 & general sociology, all areas & \\
\hline 21.8 & specific approaches, substantive areas & \\
\hline 16.4 & historical roots, classical theory & \\
\hline 10.9 & contemporary theory & \\
\hline 10.9 & theory construction, model building, logic & \\
\hline 10.9 & theory application, research & \\
\hline 3.6 & philosophical roots & \\
\hline 1.8 & how to do theory & \\
\hline 1.8 & conceptual skills & \\
\hline 1.8 & what distinguishes theories & \\
\hline 1.8 & "real" theory & \\
\hline 1.8 & fill classical-contemporary gap & \\
\hline 1.8 & interdisciplinary & \\
\hline 3.6 & missing, no answer & \\
\hline
\end{tabular}

in classical and contemporary theory is superior to training in logic and theory construction. A number of respondents further offered that theory construction and logic are less essential or important than classical and contemporary and/or that logic and theory construction are covered reasonably well in other required theory courses.

Respondents also were asked whether they believed graduate students in sociology should receive more training in theory and, if so, in what areas. Results appear in Table 4 . Respondents agreed overwhelmingly that more training in theory is needed. However, the lower portion of the table shows there to be much less agreement on what kinds of additional training would be desirable. These data also permit us to infer rates of satisfaction with different kinds of theory training: 87 percent of respondents cited no specific weaknesses in classical theory training, and 92 percent appeared satisfied with training in both contemporary theory and theoretical methods.

\section{Role of Theory}

To help us understand the teaching emphases revealed thus far, it should be informative to gauge instructors' personal opinions on the roles that theories play in sociology. We asked respondents directly about the "proper role" of theory in sociology, with results summarized in Table 5. References to intellectual and empirical aspects were equally frequent (about 43 percent), and another 14 percent 
TABLE 5

Proper Role for Theory in Sociology (124 Responses)

\begin{tabular}{cl}
\hline Proportion & Role for Theory ... \\
\hline $43.5 \%$ & Intellectual Benefits \\
14 & it is central/essential/foundational \\
10 & forms explanations; makes sense of things \\
8 & past work/classics provide orientation/perspective \\
7 & generates insights \\
6 & intellectual tool; tool kit \\
4 & offers propositions, principles; systematizes \\
2 & abstract, conceptual \\
3 & other \\
$42.7 \%$ & Empirical Benefits \\
23 & provides questions/guides/basis for research \\
15 & Puts facts/phenomena in theoretical context \\
7 & expansion, refinement, cumulation, generalization; reciprocal \\
4 & relationship with data \\
4 & adjudicates questions \\
$13.7 \%$ & empirical descriptions/testable hypotheses \\
10 & Miscellaneous \\
2 & focal point for community of researchers; communication; bridges \\
5 & mode of discourse \\
\hline
\end{tabular}

emphasized the other issues listed in the table. When asked about the proper role for theory in science more generally (results not shown in the table), 66 percent (forty-seven) gave essentially the same answer as for theory's role in sociology, and 14 percent (ten) did not answer or did not know. Another 20 percent (fourteen) cited specific differences. Five respondents from this last category actually cited differences in application (e.g., sociological theory as "a way to understand the sociological imagination") rather than differences in the nature of theory per se.

In response to the question, "What is the most important message about theory that you pass along to students?" 34 percent (39 out of 114 responses) cited theory as providing explanations and predictions for empirical phenomena. Other key messages about theory included emphases on providing general orientations (20 percent), the importance of the classics or the history of ideas (18 percent), theory as culturally bound or as socially constructing phenomena (9 percent), theory-building skills ( 9 percent), theory as central to science ( 2 percent), and miscellaneous (8 percent).

\section{Sociology as Science}

Two questions addressed the status of sociology as a science. The first asked whether our discipline qualifies as a science, with results in Table 6a. Just under 
TABLE 6a

Does Sociology Qualify as a Science?

\begin{tabular}{lcc}
\hline Response & Frequency & Proportion \\
\hline Yes & 33 & $49.3 \%$ \\
No & 10 & $14.9 \%$ \\
Mixed & 24 & $35.8 \%$ \\
No answer & 4 & \\
Sum & 71 & \\
\hline
\end{tabular}

TABLE $6 \mathrm{~b}$

Should Sociology Be More/Less Scientific?

\begin{tabular}{lcc}
\hline Response & Frequency & Proportion \\
\hline More & 23 & $36.5 \%$ \\
Fine as is & 25 & $39.7 \%$ \\
Less & 9 & $14.3 \%$ \\
Mixed & 6 & $9.5 \%$ \\
No answer & 7 & \\
Don't know & 1 & \\
Sum & 71 & \\
\hline
\end{tabular}

TABLE $6 \mathrm{c}$

Cross-Tabulation

\begin{tabular}{|c|c|c|c|c|c|}
\hline & & Sociol & ualify & Science? & \\
\hline & & Yes & No & Mixed & Sum \\
\hline Should & More & 14 & 3 & 6 & 23 \\
\hline sociology be & Fine as is & 15 & 3 & 5 & 23 \\
\hline more/less & Less & 1 & 0 & 7 & 8 \\
\hline scientific? & Mixed & 1 & 2 & 3 & 6 \\
\hline & Sum & 31 & 8 & 21 & 60 \\
\hline
\end{tabular}

a"No answer" and "Don't know" responses are excluded.

half (thirty-three) said "yes," ten said "no," and twenty-four gave a mixed response (e.g., that some parts of the field are scientific and some are not). A follow-up question asked whether sociology ought to be more scientific (Table 6b). Twenty-three said "yes," twenty-five felt that it is fine as it is, nine claimed it should be less scientific, and six gave mixed responses. Cross-tabulating these two sets of responses (Table 6c) and converting to percentages, we observe that among those who believe that sociology is a science, 45 percent think it should be more scientific and 3 percent less so. Of those who believe sociology is not a science, 
TABLE 7

What Makes a Field "Scientific" or not? (115 responses)

\begin{tabular}{cl}
\hline $\begin{array}{l}\text { Proportion } \\
\text { Frequency }\end{array}$ & \\
\hline $50.4 \%$ & Theoretical Criteria \\
27 & testing theory; falsifiability \\
12 & propositions/laws/principles explain/predict particulars \\
7 & cumulative, refinement, revision \\
4 & mathematization, formalization \\
3 & theory-driven research \\
5 & other \\
$27.8 \%$ & General Qualities \\
11 & rigorous, systematic \\
6 & sharing knowledge among members of field \\
3 & objectivity \\
2 & self-correcting \\
2 & critical \\
2 & field is self-conscious in approach to knowledge \\
2 & use scientific method \\
4 & other \\
$14.8 \%$ & Empirical Criteria \\
6 & replicability, reliability \\
4 & generalization of findings \\
2 & open to unexpected findings \\
5 & other \\
$7.0 \%$ & Social Constructionism \\
6 & labels itself as scientific \\
2 & authorities/society perceive it to be scientific \\
7 & Missing \\
6 & don't know \\
2 & no answer \\
\hline & incomprehensible \\
\hline
\end{tabular}

38 percent believe it should be more scientific and 38 percent feel that it should be even less so.

We also observed significant variability among the criteria offered for establishing the scientific status of a field. As shown in Table 7, half pertained to theory, a little over a quarter were general qualities such as rigorousness and objectivity, about 15 percent cited empirical qualities, and several respondents offered social constructionist criteria.

\section{Orientations Toward Science and Theory}

The last block of questions asked whether respondents portray classical theory, contemporary theory, formal theory, and science to their students in a positive or 
TABLE 8a

Teaching Orientations

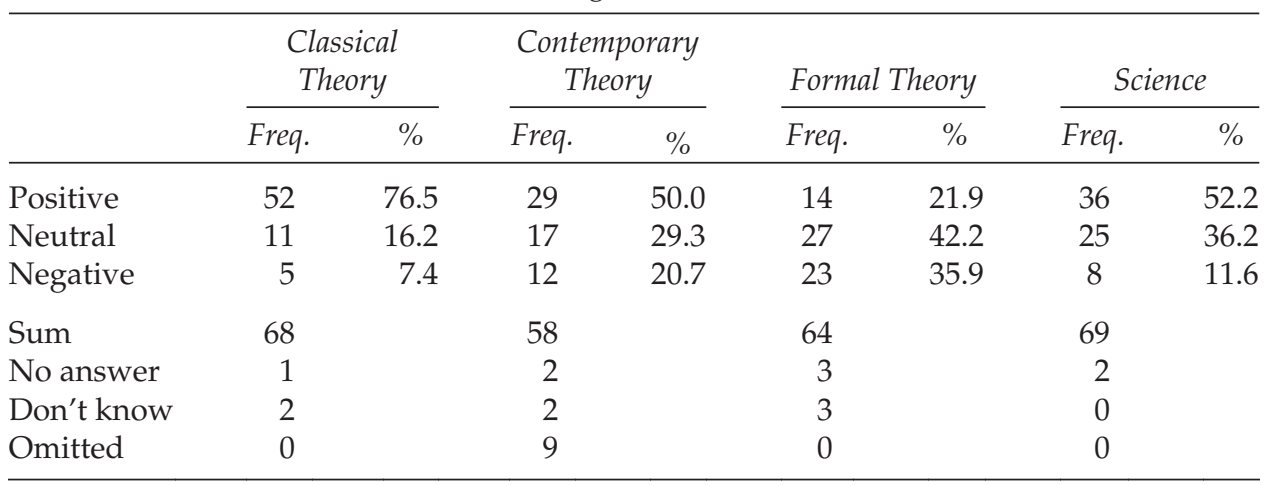

negative light. Table $8 \mathrm{a}$ shows the frequencies and proportions of respondents expressing each orientation. The results indicate that instructors promote classical theory above contemporary theory, formal theory, and science. Positive orientations toward classical theory exceed negative orientations by more than a factor of ten. Also, about half of the respondents portray contemporary theory in a positive light. However, the ratio of positives to negatives for contemporary theory was only 2.4 , compared to 10.3 for classical.

As shown in the correlation matrix (Table 8b), formal theorizing-the most negatively regarded of the four theoretical activities - exhibited the most extreme correlations: .38 with science, -.32 with classical theory. In advanced sciences, formalization is the taken-for-granted method for building and expressing theories. Whereas this could account for the relatively high formalization-science correlation, the patterns differed with respect to their relationships to classical and contemporary theory. Compared to orientations toward science, the negative correlation of formal theory with classical theory is considerably stronger, but the correlations of orientations toward formal theory and contemporary theory are considerably weaker. These results indicate a disjuncture between conceptions of science and conceptions of formal theory.

TABLE $\mathbf{8 b}$

Correlation Matrix ${ }^{\mathrm{a}}$

\begin{tabular}{lccc}
\hline & Science & Formal & Contemporary \\
\hline Classical & -.17 & -.32 & .15 \\
Contemporary & -.20 & -.01 & \\
Formal & .38 & & \\
\hline
\end{tabular}

approximate critical values for two-tailed significance tests $(n=65): \pm .31$ for $p<.01$; \pm .24 for $p<.05 ; \pm .20$ for $p<.10$. 


\section{DISCUSSION}

The foregoing results provide fairly clear and coherent answers to the research questions, as well as fodder for interpretation and discussion.

\section{"What Is Being Taught?" and "How and Where Were Instructors Trained?"}

By asking instructors about their own training and then dividing the sample into earlier and later PhDs, we could determine whether and how theory training changed across a generation. One constant is the longstanding inclusion in all graduate curricula of Marx, Weber, and Durkheim. Brint and LaValle (2000) reported similar findings. In a sample of the Theory Section of the American Sociological Association, respondents named theorists whose work they teach, or would teach, in classical and contemporary theory classes. Their ranking of the top five classical theorists matched that of the present study, though with a much smaller gap between Marx (Number 3) and Simmel (Number 4).

Just as constant as sociology's attachment to a small classical core is its minimal training in theoretical methods. Our evidence shows that few respondents expressed concerns about the absence of such material in their own training, their students' training, or nationwide, and even fewer assigned readings in the area. Only about one in five said that they portray formal theoretical methods in a positive light to their students.

There was much less consensus on other essential classical theorists or on any contemporary theorists. Required contemporary theory courses are common in our leading graduate programs, but the material they cover is idiosyncratic. The lack of uniformity does not appear to raise much concern, however, with only about one in five respondents portraying contemporary theory to their students in a negative light. (For classical theory, the number is about one in fifteen.) Very few cited any shortcomings in how either classical or contemporary courses are taught.

Despite the small size of sociology's theoretical core and its dissensus on other essential readings, a larger pattern seems to be constant across generations: the relative emphasis and value attached to (from high to low) classical theory, contemporary theory, and theoretical methods. The pattern recurs across measures, including courses taken by respondents, courses they teach, readings they assign, and how favorably they portray these topics in classes.

It is not so astonishing to find that top departments produce students who get jobs in top departments. However, it was a bit surprising to find so many instructors coming out of so few departments. That an elite set of graduate programs accounts disproportionately for instructors of required theory courses may be a stabilizing factor insofar as the above macropatterns of theory training (e.g., the dearth of theoretical methods courses). To those who believe that theory training in the elite core is top notch and that their knowledge should be disseminated through the discipline and across time, the observed hegemony is a good thing. For those who believe that theoretical methods training or any other innovation would be a good thing, prevailing conditions would inhibit its diffusion. 


\section{"What Do Instructors Think. . . ?"}

Instructors expressed relatively high levels of satisfaction with their own training and with what they teach in required theory courses. Overall, they rated nationwide training in classical and contemporary theory as only good to fair, but other responses suggest that this may be due to insufficient quantity rather than quality: They strongly favored more theory training but apparently more of the same kinds of training. To the degree that some expressed dissatisfaction with what is actually taught, it was not for want of increased rigor or greater adherence to scientific practices. A significant proportion of respondents expressed sentiments ranging from disinterest to contempt toward the idea of rigorous theoretical methods. That the quality of such methods training nationwide is only "fair" or worse was not seen as problematic to most.

A high proportion of respondents regarded theory as playing essentially the same role in sociology as in science: making sense of things, generating new insights, systematizing knowledge, organizing facts, guiding research, and so on. This is also reflected in the plurality of responses to the question regarding the most important message about theory communicated to students. The difference, apparently, is that most theory instructors in sociology feel it is sufficient to adopt an intuitive approach to the construction and analysis of theories. In more advanced scientific fields, students learn to express and evaluate theories via formal languages that lay bare the logic of their arguments and the interpretations of their terms - consistent with the presuppositions. In contrast, sociological theorizing is far more complex than, say, physics theorizing insofar as the structure of our discursive arguments and the quantity and connotations of our many terms. With theories so numerous and complex and a discipline ostensibly built on theoretical arguments and empirical validations, it is difficult to conceive of any sound defense for the practice of relying so heavily on unchecked intuitions.

Sociology encompasses activities that qualify as scientific by any definition, but it also contains a healthy share of work that nobody claims to be scientific. "Mixed" would seem to be the accurate response to the question of sociology's status as a science, however two-thirds of instructors had more polarized views, with "yes" outnumbering "no" by more than three to one. The disparate views may be due to the wide variety of criteria for science that instructors took into consideration, as indicated by responses to the question on what makes fields scientific. It also may be a case of "the blind men and the elephant," whereby conclusions regarding the big, multifaceted field are extrapolated from intimate knowledge of only certain limited parts.

The chances of actual change toward or away from scientific status depend in part on what respondents wish for our discipline. Those who are satisfied or have mixed views on sociology's scientific status form a clear plurality at 49 percent; 37 percent want us to be more scientific, 14 percent less. It seems unlikely that we will see any concerted push toward a more scientific direction by instructors of required theory courses and even less likely in a nonscientific direction. For those of us who believe that sociology would benefit by moving closer to practices consistent with the presuppositions (clearer propositions, more logical arguments, 
greater precision, generality, and accuracy), we can at least be glad for this evidence against the likelihood of backsliding-assuming that instructors' views are reflected in their teaching practices, as discussed next.

Returning to the questions on how instructors portray different areas, responses were indeed consistent with other reported attitudes and practices. The affinity for classical theory was clear insofar as how positively the four areas are portrayed to graduate students, and the ambivalence toward contemporary theory is not surprising given the lack of any consensus on essential content. The disjuncture between responses for science ( 52 percent positive) and formal theory (22 percent positive) is curious, however, and may indicate some misunderstanding about one or the other. On one hand, formal language and logic are the semantic and syntactic media of science and thus inseparable from it. On the other hand, for some sociologists, "formalization" may imply an unnatural sterility regarded as a problem for humanistic fields but not for science in general. This brings us to a discussion of some implications.

\section{"What Are the Implications for Advancement of the Field?"}

Judging by other responses they provided, it is possible that a subset of instructors expressing disinterest (or worse) toward formal theory and science were reacting to stereotypes that are far more extreme than the criteria expressed in the presuppositions. Of formalization, one respondent said, "Models and logic [become] so tight that no substantive area or ideas ever seep in so it's actually dysfunctional." Another observed, "Theory construction has been unable to take human historicity into account." In fact, nothing in the methods of theory construction or formalization prohibit taking into account any substantive factor that one feels is relevant to the argument, including historicity. The methods are only to promote clarity (e.g., requiring the theorist to specify what she means by "historicity"), organize statements (e.g., being explicit about what he claims is affected by historicity and how), prevent self-contradiction, guide empirical analysis, and so on. If portrayed this way, it is possible that some (but not all) instructors would have expressed more positive views - to us and to their students-about science, logic, formalization, and theory construction.

In science, it is difficult to conceive of progress without formalization-without adherence to presuppositions requiring clarity of terms, transparency of arguments, and empirical verisimilitude. This is not to say that sociology fails to score well by some meanings of "progress." We publish a lot, we generate new insights, we conduct a lot of research, and we learn a lot about a lot of things. But everexpanding inventories of ideas and observations do not necessarily add up to much. Science demands cumulative knowledge, a kind of evolutionary advancement by which weaknesses in theories are identified and strengthened through a process of testing, refinement, and competition. This kind of progress requires formalization, consistent with the presuppositions. By this standard, progress is occurring in some areas of sociology, but the lion's share of sociological work is not cumulative (Freese 1980; Wagner and Berger 1985). That we have a number of old theories still considered viable is one indication of the problem, but it is more 
than that. With theoretical methods left to intuition, there are no norms for building and analyzing theories and no toolkits to share with nascent sociologists in their required theory courses. Such tools do exist and have been around a very long time but simply have not broken through the walls of our pedagogies and practices.

There is a sense in which having diverse perspectives strengthens fields of inquiry, and one might argue that using nonrigorous and intuitive theoretical methods provides alternative viewpoints. This argument seems unsustainable, however, in the same way that using "alternative arithmetic" is unlikely to provide useful insights when balancing a checkbook. Alternative perspectives enacted through competing explanations are always worth considering, but formalization operates at a deeper level. If an argument is invalid, for example, then so is the outcome of any empirical test of it. If a term is ambiguous, then so is any statement that employs it, along with the relevance of any observation presumed to bear upon it. Not all methodological perspectives are useful in the sense of helping to make ideas and observations cumulate. In fact, the scientific approach is the only one we know that accomplishes this.

Earlier I drew distinctions between activities occurring at the stage of theory development versus others at the stage of theory evaluation. In practice, these processes operate hand in hand, but each has a distinct character. Devising new theories or modifying existing ones is inherently creative, and it makes sense to have at one's disposal a broad array of prior thinking-classical, contemporary, postmodern, or whatever one chooses-from which to draw ideas and inspiration. Evaluating a new theory or a new modification of a theory is an entirely different matter. It is here that proponents of a theory must offer sound reasons to support its plausibility, just as any critic must justify his or her claims against it. In the absence of shared, well-founded criteria for conducting such evaluations, it is inevitable that the field will reject good theories that would have provided relatively broad and accurate accounts of social phenomena, and it will uphold bad theories whose appeal is based on factors other than veracity. Absent a reliable filter for retaining only the best work, progress is impeded (Markovsky 1997). The benefits of that filter would be evident in accelerated, cumulative, discipline-wide progress.

\section{CONCLUSION}

The sociologists interviewed for this project were in positions of influence with respect to the theoretical orientations of present and future generations of scholars. Still, one could argue that it is inconsequential whether theory courses across the discipline are rigorous or mutually consistent. The argument is this: The content and normative practices communicated in required empirical methods and statistics courses are far more uniform across departments than those communicated in required theory courses, and these courses supply whatever rigor may be lacking in theory courses. Therefore, this ought to allay concerns that students of the discipline are not well equipped to approach their field in an intellectually rigorous way - to reject bad theoretical ideas on empirical grounds and to promote only the good ones. There is a problem with this chain of reasoning, perhaps 
obvious: It implies that a field's progress may be sustained by empirical analysis alone, regardless of the state of its theories. In fact, no amount of empirical sophistication can substitute for a lack of movement on the theoretical frontier. Once again, this is because empirical observations are not theoretical knowledge no matter how cutting-edge the empirical methodology.

If disciplines truly advance on their theories, then the burden of progress must be carried by methodologies both empirical and theoretical. This is why it is not sufficient merely to allow a thousand theoretical flowers to bloom so that we might stand back and admire the landscape or to conduct a thousand empirical studies in hopes that knowledge somehow will blossom from them. This is why enhancing the way we teach the construction and the rigorous evaluation of theories will lead to more reliable and valid sociological knowledge. The criteria that we teach students to apply to their own and others' work can be neither esoteric nor idiosyncratic. The evidence shows that our collective disinterest in theoretical methods is stronger even than our support for the classics. It is as though sociology has managed to locate spectacular sources of inspiration but remains uncertain about how to pursue them.

\section{APPENDIX A \\ INTERVIEW INSTRUMENT (SELECTED ITEMS)}

\section{[Courses and Readings]}

1. Is it correct that your course is required for all $\mathrm{MA}$ and $\mathrm{PhD}$ students?

2. What is the typical annual enrollment for the course?

3. What do you consider to be the three or four most essential readings?

4. Looking back, would you say that your own training in theory was adequate? (If not, why?)

\section{[Source and Quality of Instructors' Training]}

5. Where did you receive your PhD? What year?

6. What emphases were there in required theory courses you took as a graduate student?

\section{[Quality of Theory Training]}

7. Do you believe that graduate students in sociology should be taught more about theory? If so, what areas?

[8 to 15 response scale: excellent, very good, good, fair, poor]

8. Nationwide, how would you rate the quality of graduate training in classical theory?

9. Nationwide, how would you rate the quality of graduate training in theory construction?

10. Nationwide, how would you rate the quality of graduate training in formal logic?

11. Nationwide, how would you rate the quality of graduate training in contemporary theory? 


\section{[The Role of Theory]}

12. What's the most important message about theory that you pass along to students?

13. What do you believe is the proper role for theory in sociology?

14. What would you say is the proper role for theory in science more generally?

\section{[Sociology as a Science]}

15. Based on its published work, would you say that sociology qualifies as a science?

16. Do you think sociology should be more scientific, less so, or is fine as is?

\section{[Orientation toward Science and Theory]}

17. When you teach theory, would you characterize your approach overall as being relatively favorable toward science, neutral, or somewhat negative toward science?

18. Relative to sociologists as a whole, would you say that you feel more favorably disposed toward classical theory, less favorable, or about average?

19. Relative to sociologists as a whole, would you say that you feel more favorably disposed toward formal theorizing, less favorable, or about average?

20. Relative to sociologists as a whole, would you say that you feel more favorably disposed toward contemporary theory, less favorable, or about average?

\section{APPENDIX B}

\section{TOP FIFTY GRADUATE PROGRAMS IN SOCIOLOGY, U.S. NEWS AND WORLD REPORTS (1998)}

University of Arizona

Boston University

Brandeis University

Brown University

U.C. Berkeley

U.C. Davis

UCLA

U.C. Riverside

U.C. San Diego

U.C. Santa Barbara

University of Chicago

CUNY

Columbia University

University of Michigan

Michigan State University

University of Minnesota
Cornell University

Duke University

Emory University

Florida State University

University of Georgia

Harvard University

University of Illinois

University of Illinois, Chicago

Indiana University

University of Iowa

Johns Hopkins University

University of Maryland

University of Massachusetts

SUNY Albany

SUNY Binghampton

SUNY Stonybrook 
New School

University of North Carolina

Northwestern University

New York University

Ohio State University

University of Pennsylvania

Penn State University

Princeton University

Rutgers University

Stanford University
University of Southern California

University of Texas, Austin Vanderbilt University

University of Virginia

University of Washington

Washington State University

University of Wisconsin

Yale University

Acknowledgments: The project was partly funded by a grant from the American Sociological Association. Integral to the project were the many hours of assistance provided by Chris Barnum, Cynthia Estep, Will Kalkhoff, John Knapp, and Wes Younts. Helpful feedback on preliminary versions was provided by Casey Borch, David Willer, and attendees of presentations at the Annual Meetings of the American Sociological Association, the Iowa Workshop for Theoretical Analysis, and the Department of Sociology at the University of South Carolina. Special thanks to an anonymous reviewer from this journal whose numerous suggestions improved this article significantly.

\section{NOTES}

1. These presuppositions are normative in scientific disciplines, and though widely shared in the social sciences, they are not universally accepted-as later the evidence will confirm. In elaborating related presuppositions, Cohen (1980) provided methods and criteria for developing concepts and definitions, theoretical arguments, and theorydriven research programs. Cederblom and Paulsen (2005) provided methods for analyzing informal arguments, a characterization that captures the lion's share of what passes for sociological theorizing. "Formalization" often conjures images of complicatedlooking mathematical arguments, but both of the cited treatments allow formal theories to be expressed in natural language.

2. Halfpenny (1982) showed that numerous meanings have been associated with "positivism," and the label is useless without first specifying its intended meaning.

3. To presume that a word has inherent meaning is to commit the essentialist fallacy (i.e., the belief that words have true essences distinct from the meanings that people assign to them; Popper 1965: ff103). We commit this fallacy whenever we proclaim that the use of a particular definition for a term is truer (e.g., more representative of some class of empirical objects) or less true than alternatives. The orientation explicated in this work favors some definitions for "theory" over others, not because they are inherently correct or used more frequently but because they are better suited to serving the ends described in the presuppositions-most importantly, precision, generality, and accuracy.

4. For our purposes, "progress" is conceptualized via the criteria expressed in the presuppositions.

5. Cohen and Nagel (1934: 215-16) were among the first to bring this issue to light.

6. Objective methods for theory construction are not antithetical to methods commonly labeled as subjectivist, interpretive, inductive, or qualitative if one recognizes distinctions 
between the generation of theoretical ideas (which may be highly subjective) and the expression and evaluation of those ideas. If accurate communication and collective evaluation are to transpire, then at some point subjective knowledge must be transformed into expressions whose semantic, logical, and empirical content can be evaluated via objective methods.

7. Logicians sometimes refer to this as the "fallacy of fake precision."

8. Some items not pertinent to this discussion were omitted.

9. Interviews were conducted between 1999 and 2000. Departments from the 1998 U.S. News listing are shown in Appendix B. Respondents to that survey were department heads and directors of graduate programs at schools that had granted five or more doctoral degrees during the period 1991-1995. Notably, the rankings have changed very little in the past dozen or more years.

10. The sample of interviewees was a moving target. Some departments were flexible insofar as how requirements could be satisfied, some of the required courses had revolving instructors, and others lacked any instructors because of recent personnel changes. Our sample consisted overwhelmingly—but not entirely-of faculty who regularly taught courses that fulfill graduate theory requirements.

11. The only disagreements occurred in coding several responses either as "missing" versus "not answered," the latter referring to cases where the interviewee did respond but not in a manner that addressed the question asked. Such divergences are easily resolved and do not affect substantive analyses.

12. In one case, a course was not explicitly required, but as verified by two members of the department, literally "everyone takes it".

13. Following Münch (1994a, 1994b), the line between classical and modern periods was drawn in the 1920s. By this convention, George Herbert Mead was the latest of the classical scholars cited in our study. Also, our classical category includes "history of social thought," and the modern/contemporary category includes any reference to nonclassical theories. However, neither category includes "general theory" nor other responses that fail to distinguish classical theories from others.

14. The Gini index was 0.41 for these data. A Gini of 1.0 would occur if all instructors received PhDs from the same department, and a Gini of 0 would indicate equal representation of instructors across all $\mathrm{PhD}$ departments. By way of comparison, the observed value is roughly the same as the Gini indices for wealth and income inequalities in the United States.

15. Some respondents provided multiple responses. Here and elsewhere, tables indicate whether proportions are based on the number of responses or the number of respondents.

16. For these data and others reported below, response categories were inferred from instructors' statements. As with any such qualitative analysis, there were some judgment calls in the coding process. To help safeguard against possible biases, key excerpts and paraphrases appear in the relevant tables, and transcripts are available for further analysis upon request. Most of the coding was very straightforward and did not seem to require any "judgment calls." However, data sharing with independent researchers also would be desirable in this case. Intercoder reliability checks were conducted with the author and several project assistants, but the assistants' training very likely was affected by the author and could have inflated the apparent reliability. 


\section{REFERENCES}

Brint, Steven and James LaValle. 2000. "DuBois Ascendant! And Other Results from the Brint-LaValle Theory Section Survey." Perspectives (The American Sociological Association Theory Section Newsletter) 22 (1): 1, 3, 7.

Campbell, Donald T. 1974. "Evolutionary Epistemology." Pp. 413-63 in The Philosophy of Karl Popper, Book I, edited by P. A. Schilpp. La Salle, IL: Open Court Press.

Cederblom, Jerry and David W. Paulsen. 2005. Critical Reasoning, 6th ed. Belmont, CA: Wadsworth.

Cohen, Bernard P. 1980. Developing Sociological Knowledge. Chicago: Nelson-Hall.

Cohen, Morris and Ernest Nagel. 1934. An Introduction to Logic and Scientific Method. New York: Harcourt, Brace.

Dilks, Lisa, Kyle Irwin, and Barry Markovsky. 2006. “Finding a Theory in a Haystack." Presented at the Annual Meetings of the American Sociological Association, Montreal, Canada.

Fales, Evan and B. Markovsky. 1997. "Evaluating Heterodox Theories." Social Forces 76 (2): 511-25.

Freese, Lee. 1980. "The Problem of Cumulative Knowledge." Pp. 13-69 in Theoretical Methods in Sociology: Seven Essays, edited by L. Freese. Pittsburgh, PA: University of Pittsburgh Press.

Halfpenny, Peter. 1982. Positivism and Sociology: Explaining Social Life. Boston: Allen \& Unwin.

Markovsky, Barry. 1997. "Evolution and Nebulousness in Theories." Current Research in Social Psychology 2 (3): 24-29. Available at http:/ / www.uiowa.edu/ grpproc/crisp/ crisp.2.3.html

Münch, Richard. 1994a. Sociological Theory, Volume 1: From the 1850s to the 1920s. Chicago: Nelson-Hall.

. 1994b. Sociological Theory, Volume 2: From the 1920s to the 1960s. Chicago: NelsonHall.

Popper, Karl R. 1965. Conjectures and Refutations: The Growth of Scientific Knowledge. New York: Harper Torchbooks.

Wagner, David G. and Joseph Berger. 1985. "Do Sociological Theories Grow?" American Journal of Sociology 90 (4): 697-728. 
